\title{
Injectable iodine-125 labeled tissue marker for radioactive localization of non-palpable breast lesions
}

Schaarup-Jensen, Henrik; Jensen, Andreas Ingemann; Hansen, Anders Elias; El Ali, Henrik H.; Hammershøj, Peter; Jølck, Rasmus Irming; Kjær, Andreas ; Andresen, Thomas Lars; Clausen, Mads Hartvig

\section{Published in:}

Acta Biomaterialia

Link to article, DOI:

10.1016/j.actbio.2017.10.029

Publication date:

2018

Document Version

Peer reviewed version

Link back to DTU Orbit

Citation (APA):

Schaarup-Jensen, H., Jensen, A. I., Hansen, A. E., El Ali, H. H., Hammershøj, P., Jølck, R. I., Kjær, A.,

Andresen, T. L., \& Clausen, M. H. (2018). Injectable iodine-125 labeled tissue marker for radioactive localization of non-palpable breast lesions. Acta Biomaterialia, 65, 197-202. https://doi.org/10.1016/j.actbio.2017.10.029

\section{General rights}

Copyright and moral rights for the publications made accessible in the public portal are retained by the authors and/or other copyright owners and it is a condition of accessing publications that users recognise and abide by the legal requirements associated with these rights.

- Users may download and print one copy of any publication from the public portal for the purpose of private study or research.

- You may not further distribute the material or use it for any profit-making activity or commercial gain

- You may freely distribute the URL identifying the publication in the public portal 
Injectable iodine-125 labeled tissue marker for radioactive localization of non-palpable breast lesions

Henrik Schaarup-Jensen ${ }^{\mathrm{a}}$, Andreas Ingemann Jensen ${ }^{\mathrm{b}}$, Anders Elias Hansen ${ }^{\mathrm{c}}$, Henrik H. El Ali ${ }^{\mathrm{d}}$, Peter Hammershøj $^{\mathrm{a}}$, Rasmus Irming Jølck ${ }^{\mathrm{c}}$, Andreas $\mathrm{Kjær}^{\mathrm{e}}$, Thomas L. Andresen ${ }^{\mathrm{c} *}$, and Mads H. Clausen ${ }^{\mathrm{a} *}$

${ }^{a}$ Center for Nanomedicine and Theranostics, Department of Chemistry, Technical University of Denmark, Building 207, Kemitorvet, 2800 Kgs. Lyngby, Denmark

${ }^{\mathrm{b}}$ Center for Nanomedicine and Theranostics, Center for Nuclear Technologies (DTU Nutech), The Hevesy Laboratory, Technical University of Denmark, Building 202, Frederiksborgvej 399, 4000 Roskilde, Denmark

${ }^{\text {c }}$ Center for Nanomedicine and Theranostics, Department of Micro-and Nanotechnology, Technical University of Denmark, Building 345E, Ørsteds Plads, 2800 Kgs. Lyngby, Denmark

d Section of Cellular and Metabolic Research, Department of Biomedical Sciences, University of Copenhagen, 42.2, Building 10-5-15, Blegdamsvej 3b, 2200 København N

${ }^{\text {e }}$ Department of Clinical Physiology, Nuclear Medicine \& PET and Cluster for Molecular Imaging Rigshospitalet and University of Copenhagen, Blegdamsvej 9, 2100 Copenhagen, Denmark

* Corresponding authors: Thomas L. Andresen, E-mail: thomas.andresen@nanotech.dtu.dk Tel.: +4545258168; Mads H. Clausen, E-mail: mhc@kemi.dtu.dk Tel.: +4545252131Contact information: hensaar@kemi.dtu.dk (Henrik Schaarup-Jensen), atije@dtu.dk (Andreas Ingemann Jensen), aeha@sund.ku.dk (Anders Elias Hansen), helali@sund.ku.dk (Henrik H. El Ali), P.Hammershoj@hotmail.com (Peter Hammershøj), rasj@nanotech.dtu.dk (Rasmus Irming Jølck), akjaer@sund.ku.dk (Andreas Kjær) 


\begin{abstract}
We have developed a ${ }^{125}$ I-radiolabeled injectable fiducial tissue marker with the potential to replace current methods used for surgical guidance of non-palpable breast tumors. Methods in routine clinical use today such as radioactive seed localization, radio-guided occult lesion localization and wireguided localization suffers from limitations that this injectable fiducial tissue marker offers solutions to. The developed ${ }^{125}$ I-radiolabeled injectable fiducial tissue marker is based on highly viscous sucrose acetate isobutyrate. The marker was readily inserted in NMRI mice and proved to be spatially well-defined and stable over a seven day period with excellent CT contrast (>1500 HU), enabling fluoroscopic visualization of markers during placement. The radioactivity remains strongly associated with the marker during the implantation period, which limits exposure to healthy tissue. Biodistribution studies show that there is negligible radioactivity in all non-tumor tissues sampled, with the exception of the thyroid gland, where limited accumulation was observed $(0.06 \%$ of injected dose after 7 days). Based on the excellent performance of the marker and the fact that it can be delivered through thin hypodermic needles $(\geq 27 G)$, the marker holds great promise for clinical application, since patient discomfort is reduced significantly compared to current methods.
\end{abstract}

Keywords: breast-conserving surgical procedures; radioiodination; CT contrast; radiopaque fiducial marker 


\section{Introduction}

With the increasing quality of mammographic imaging and the introduction of wide-ranging screening campaigns for breast cancer, non-palpable tumors are detected earlier and to a higher degree [1-3]. Consequently, breast conserving surgery (lumpectomy) has become an attractive option compared to whole-breast surgery (mastectomy) [3]. Lumpectomy shows similar long-term survival rates, but unfortunately, recurrence rates from lumpectomy are still higher than for mastectomy $[4,5]$. This can be explained by the excision procedure of non-palpable tumors, which is highly dependent on accurate target delineation (pre-localization) needed for surgical guidance $[1,2,5]$. There is a clear need for improved preoperative image-guided localization in order to improve resection and recurrence rates $[1,5]$. The present technologies for surgical guidance of non-palpable tumors within breast cancer are radioactive seed localization (RSL), where a ${ }^{125}$ I-coated titanium seed (usually 4.5 $\times 0.8 \mathrm{~mm}$ ) is inserted in the tumor; radio-guided occult lesion localization (ROLL), where technetium ( $\left.{ }^{99 \mathrm{~m}} \mathrm{Tc}\right)$-labeled particles are injected intratumorally; and wire-guided localization (WGL), where a hooked wire is inserted in the breast pointing to the site of the tumor [1-3,6-11]. The first two methods allow surgical localization of radioactive material, whereas the latter relies on the physical localization of the wire tip. Each of these methods have drawbacks: RSL seeds are inserted with widegauge (17 G) hypodermic needles. WGL is perceived as unpleasant, painful and even traumatic to patients [1,3] and associated with high rates of remaining tumor tissue post-surgery [3]. ROLL has a short window for surgery after insertion due to the $6 \mathrm{~h}$ physical half-life of ${ }^{99 \mathrm{~m}}$ Tc and furthermore cannot be visualized by computed tomography (CT) scanning [2]. Consequently, the development of functional biomaterials, which enable surgical guidance with high fidelity, reduced patient discomfort and good CT contrast properties, is highly desired. To align with current clinical practice, these materials should be based on radioactivity, which is used extensively due to the ease of detection. A radioactive liquid fiducial tissue marker enables easy tuning of the radioactivity, including dose and 
choice of isotope e.g. of iodine (I-123, I-124, I-125 and I-131), depending on the application. The fine-tuning of radioactivity further facilitates to account for Compton scattering of ${ }^{99 \mathrm{~m}} \mathrm{Tc}$, and thereby provide improved distinction between ${ }^{125} \mathrm{I}$ and ${ }^{99 \mathrm{~m}} \mathrm{Tc}$, in those cases where Sentinel Lymph Node (SLN) biopsies are needed. The difficulty in making clear distinction of ${ }^{125} \mathrm{I}$ and ${ }^{99 \mathrm{~m}} \mathrm{Tc}$ due to Compton scattering is highlighted by Pouw et al. and supported by other studies [11-13].

A promising biomaterial is sucrose acetate isobutyrate (SAIB), which is a highly viscous liquid (100 $\mathrm{Pa} \cdot \mathrm{s})$ [14]. SAIB is generally-recognized-as-safe (GRAS) by the FDA and when diluted with ethanol (20\% v/v), the viscosity is dramatically reduced (to $0.1 \mathrm{~Pa} \cdot \mathrm{s}$ [14]). This enables injection through hypodermic needles $(\geq 27 G)$ at ambient temperature [14-17]. Deposition in soft tissue results in ethanol efflux and the formation of a highly viscous, gel-like implant due to a non-solvent induced phase separation (NIPS) [14,17]. SAIB formulations have among other applications been exploited recently in the development of radiopaque fiducial markers, as a matrix for hosting well-defined gold nanoparticles as well as a highly iodinated SAIB-derivative $\left(\right.$ BioXmark $\left.^{\circledR}\right)$ [17-20]. BioXmark ${ }^{\circledR}$ was recently CE-marked and approved for clinical use as soft tissue marker for surgical procedures including radiotherapy in the EU. In order to develop a radiolabeled tissue marker for surgical guidance with radiopaque properties, a radioactive component is needed. I-125 is the preferred iodine isotope in RSL due to its attractive half-life (59 days) and low energy gamma and X-ray emissions (27-35 keV), making it well suited for radioactive detection with low exposure to the surrounding tissue [11]. This study presents the synthesis of a ${ }^{125}$ I-radiolabeled SAIB derivative $\left(\left[{ }^{125} \mathbf{I}\right] \mathbf{2}\right.$, - Figure 1 and Scheme 1) in combination with BioXmark ${ }^{\circledR}$ as a radioactive tumor marker for surgical guidance. The study includes evaluation of biodistribution, dosimetry and CT contrast properties of the formulation in a NMRI mouse model. The concept is illustrated in Figure 1. 


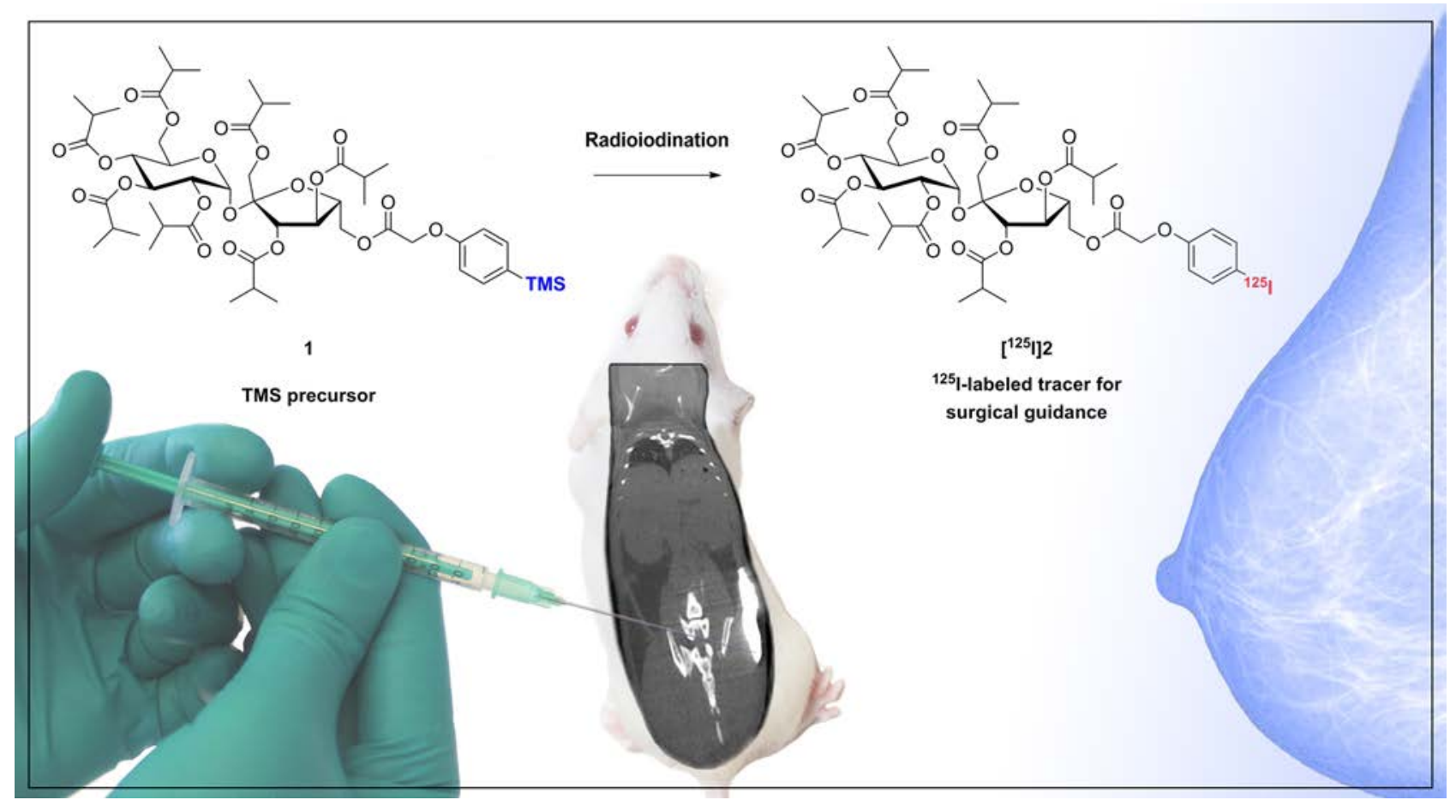

Fig. 1. The concept of the ${ }^{125}$ I-labeled tissue marker for surgical guidance. The ${ }^{125}$ I-labeled SAIBtracer $\left[{ }^{125} \mathbf{I}\right] \mathbf{2}$ and BioXmark ${ }^{\circledR}$ together constitute the radioactive fiducial tissue marker for surgical guidance. It is injectable through thin hypodermic needles $(\geq 27 G)$ and forms a gel-like implant upon injection into soft tissue based on the mechanism of NIPS.

\section{Materials and Methods}

\subsection{Synthesis}

For details of the synthesis and characterization of compound 1-4, please see Supporting Information.

\subsection{Radioiodination and formulation of [125I]2}

Precursor 1 in $\mathrm{CH}_{3} \mathrm{CN}(9.62 \mathrm{mM}, 120 \mu \mathrm{L}, 1.15 \mu \mathrm{mol})$ was transferred to a vial containing $\mathrm{Tl}\left(\mathrm{OOCCF}_{3}\right)_{3}$ in $\mathrm{TFA} / \mathrm{CH}_{3} \mathrm{CN}(5 \mathrm{~mm}, 380 \mu \mathrm{L}, 1.9 \mu \mathrm{mol})$ and the resulting solution was stirred at $20{ }^{0} \mathrm{C}$ for $105 \mathrm{~min} . \mathrm{Na}\left[{ }^{125} \mathrm{I}\right] \mathrm{I}(20 \mu \mathrm{L}, 77 \mathrm{MBq}$, iodide: $0.9 \mathrm{nmol})$ in aqueous $\mathrm{NaOH}(0.01 \mathrm{mM})$ was added and stirring was continued. Aqueous $\mathrm{NaI}(0.2 \mathrm{M}, 12 \mu \mathrm{L}, 2.4 \mu \mathrm{mol})$ was added after $15 \mathrm{~min}$ and 
again after $90 \min (6 \mu \mathrm{L}, 1.2 \mu \mathrm{mol})$. The reaction mixture was stirred for another 30 min and then diluted with $\mathrm{H}_{2} \mathrm{O}(500 \mu \mathrm{L})$. The mixture was loaded onto a SEP-PAK C18 Plus cartridge (360 mg sorbent, 55-105 $\mu \mathrm{m}$ particle size, WAT020515, Milford, MA, USA) and eluted with aqueous diethylenetriaminepentaacetic acid (DTPA, pH 7), followed by water/EtOH mixtures, with the product [ $\left.{ }^{\mathbf{1 2 5}} \mathrm{I}\right] \mathbf{2}$ eluting in pure EtOH. The thallium content and radioactivity in all fractions was measured using ICP-OES (ICAP 6000, Thermo Scientific) and well-counting, respectively (see Supporting Information, Table S3). The radiochemical yield (RCY, non decay-corrected) was $64 \mathrm{MBq}(83 \%)$ and the radiochemical purity (RCP) was $>95 \%$ by radio-TLC (see Supporting Information, Figure S1).

Formulation of [ [125I]2 was carried out by evaporation to dryness of $1.7 \mathrm{~mL}$ of the combined $\left.{ }^{[25} \mathbf{I}\right] \mathbf{2}$ fractions (60 min at $40{ }^{\circ} \mathrm{C}$ using a stream of argon). The dry residue was mixed with BioXmark ${ }^{\circledR}$ (Nanovi Radiotherapy A/S, Kgs. Lyngby, Denmark) (1.7 mL) affording the desired tissue marker $\left(38 \mathrm{MBq} \cdot \mathrm{mL}^{-1}\right)$. The radiolabeled tissue marker was stored at room temperature and used the day of the radiolabeling.

\subsection{In vivo experiments}

Immunocompetent eight weeks old female NMRI mice ( $n=12$, Taconic, Borup, Denmark) were injected subcutaneously in the right flank with $50 \mu \mathrm{L}$ of the ${ }^{125}$ I-radiolabeled marker using $1 \mathrm{~mL}$ syringes and 27G hypodermic needles. Injections were performed under general anesthesia (3-4\% sevoflurane in $40 \% \mathrm{O}_{2}$ and 60 medical grade air). Mice were randomized into three groups. Group one ( $n=4)$ was euthanized $1 \mathrm{~h}$ after injection of the marker and sectioned for biodistribution analysis

of ${ }^{125}$ I. Group two $(n=4)$ had CT scans performed 1, 3 and 24 hours after injection of the marker and euthanized directly after the 24 h scan for bio-distribution analysis of ${ }^{125}$ I. Group three $(\mathrm{n}=4)$ 
had CT scans performed 1 and 24 hours after injection and again $168 \mathrm{~h}$ after injection directly before being euthanized and sectioned for biodistribution analysis of ${ }^{125} \mathrm{I}$.

\subsection{Imaging}

CT scans were performed on a dedicated small animal CT scanner (75 kV, 500 mA, 280 msec rotation steps, Siemens MicroCAT, Erlangen, Germany) and the CT scans were analyzed in Inveon software (Inveon Research Workplace 3.0, Siemens Medical Solutions, Erlangen, Germany). The marker was readily identified on all CT scans and a manual volume of interest (VOI) was placed around each marker, taking care not to include bone structures. The threshold of the VOI was set to include only the sub volume comprising voxel with a Hounsfield unit (HU) value above $1500 \mathrm{HU}$ to define the marker volume and determine the CT contrast $[17,21]$.

\subsection{Biodistribution study}

Mice were anesthetized and blood drawn by cardiac puncture followed by terminal perfusion with saline. Tissue-samples of the following organs and tissues were collected at $1 \mathrm{~h}, 24 \mathrm{~h}$ and $168 \mathrm{~h}$ respectively, and transferred into pre-weighed gamma counter tubes: muscle, liver, kidney, lung, heart, thyroid gland (complete larynx), blood, spleen, brain and small intestines. The marker was easily identified as a transparent, gel-like implant and this was carefully removed and transferred to a gamma counter tube. All tubes were well-counted for 10 min using a ${ }^{125}$ I-setup and decay correction (Wizard gamma counter, Perkin Elmer, Waltham, MA. USA). The activity of the thyroid gland was determined from the overall activity in the larynx with the overlying thyroid gland, which was not further dissected to avoid damaging the thyroid and thereby risk underestimating activity. The weight of the thyroid gland was set at a fixed value of $16.5 \mathrm{mg}$. 


\subsection{Dosimetry}

Dosimetry was performed using the OLINDA software (Organ Internal Dose Assessment Code, version 1.1, Vanderbilt University, 2007) based on data from well-counted organs and tissues.

\subsection{Statistical evaluation}

The statistical evaluation and the corresponding graphical representation of data were performed using GraphPad Prism 7.03 ${ }^{\circledR}$ and Excel ${ }^{\circledR}$. Data illustrated in Fig. 3 and Fig. 4 are reported as their respective mean \pm SEM $(n=4)$. A Kruskal-Wallis comparison of the three groups in Fig. 4 was conducted in GraphPad Prism $7.03^{\circledR}$ in order to reveal significant difference between the groups (please see Results, section 3.3 and the corresponding discussion).

\section{Results}

\subsection{Synthesis \& radiolabeling}

Precursor 1 was synthesized in four steps from $p$-bromophenol 3, see Scheme 1. Metal-halogen exchange of $\mathbf{3}$ followed by treatment with TMSCl introduced the TMS-group. Phenol alkylation and ester hydrolysis afforded intermediate 4, which was coupled with 1',2,3,3',4,4',6-hepta-O-isobutyryl sucrose S3 [17] using EDC $\cdot \mathrm{HCl}$ to provide precursor 1. Different iodination conditions were investigated (see Supporting Information, Table S1 and S2) and a thallation-iodination protocol was found to be most efficient [22]. The use of thallium is a well-established, mild protocol for electrophilic iodination, but does require rigorous removal of residual thallium during purification. Non-radioactive iodination afforded 2 in $97 \%$ yield while [ ${ }^{125}$ I]2 was obtained in 83\% RCY with RCP $>95 \%$. Interestingly, the radioiodination reaction took place under carrier-free conditions before non-radioactive NaI was added, at which point the RCY was already in excess of $80 \%$. Purification 
using reverse-phase chromatography removed $>98 \%$ of all thallium through pre-elution with DTPA (Table S3) and enabled the elution of thallium-free $\left[{ }^{125} \mathbf{I}\right] 2$ ( $<10 \mathrm{ppb}$, ICP-OES).

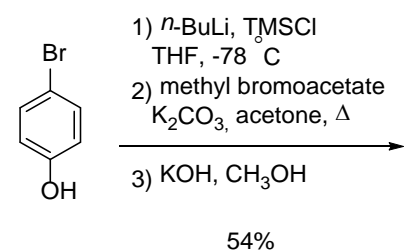

3
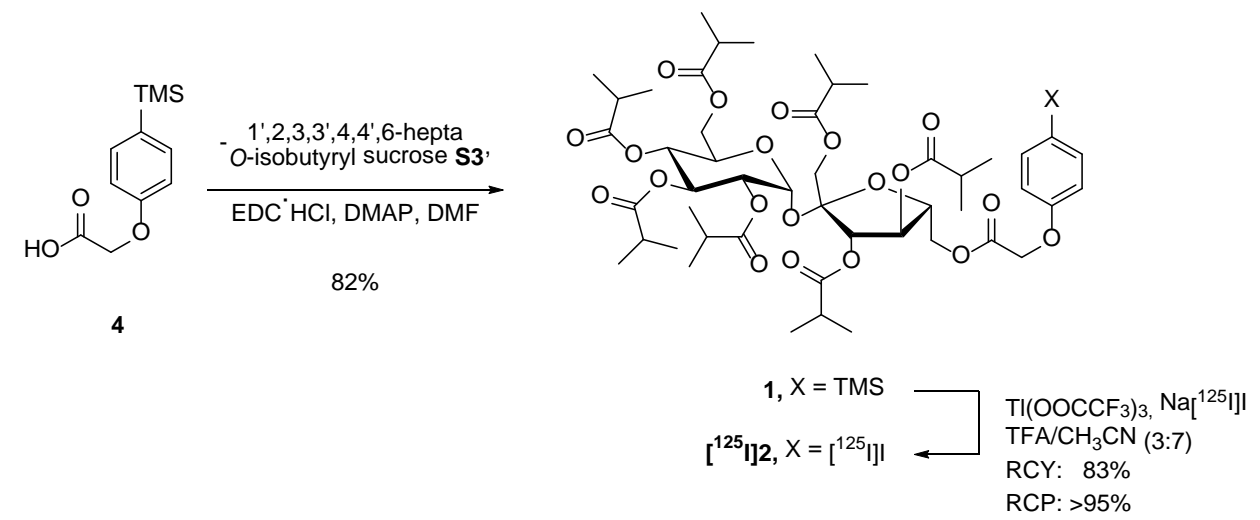

Scheme 1. The synthesis of [ $\left.{ }^{125} \mathbf{I}\right] \mathbf{2}$ from $p$-bromophenol 3.

\subsection{Imaging}

The radiolabeled marker was injected subcutaneously in the upper left flank of NMRI mice (V = 50 $\mu \mathrm{L}, \mathrm{n}=3 \times 4$ ). The injected markers were clearly visible by micro-CT imaging acquired $1 \mathrm{~h}, 24 \mathrm{~h}$ and $168 \mathrm{~h}$ post injection (Fig. 2). As can be seen from both the axial (Fig. 2A, 2C and 2E) and coronal (Fig 2B, 2D and 2F) plane, excellent positional stability of the marker was observed throughout the time of investigation and the marker was clearly identified due to the high radiopacity of the BioXmark $^{\circledR}$ formulation. The observed positional stability of the radiolabeled marker is consistent with what has been previously reported for BioXmark ${ }^{\circledR}[23]$. 


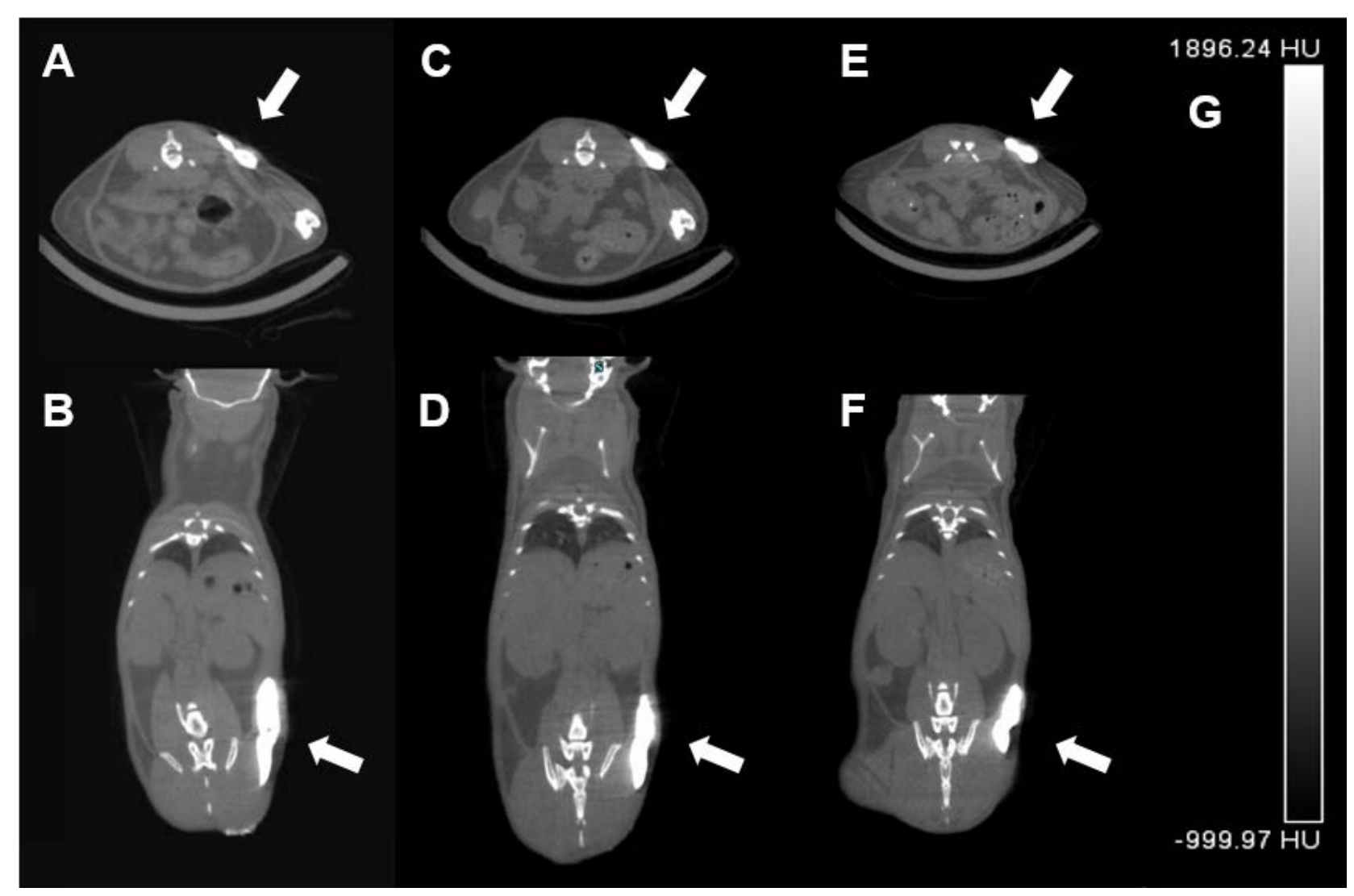

Fig. 2. Representative micro-CT images of mouse with the ${ }^{125}$ I-radiolabeled fiducial tissue marker

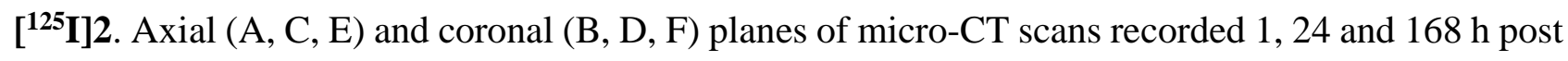
injection, respectively. Contrast scale in $\mathrm{HU}(\mathrm{G})$. The white arrows indicate the position of the tissue marker.

The marker volume and CT contrast change were evaluated by VOI-analysis of the micro-CT scans and the developments over time are depicted in Fig. 3. As can be seen, markers were found to be stable and the observed reduction in marker volume (Fig. 3A) and increase in CT contrast (Fig. 3B and 3C) were consistent with ethanol efflux $[17,21]$. 

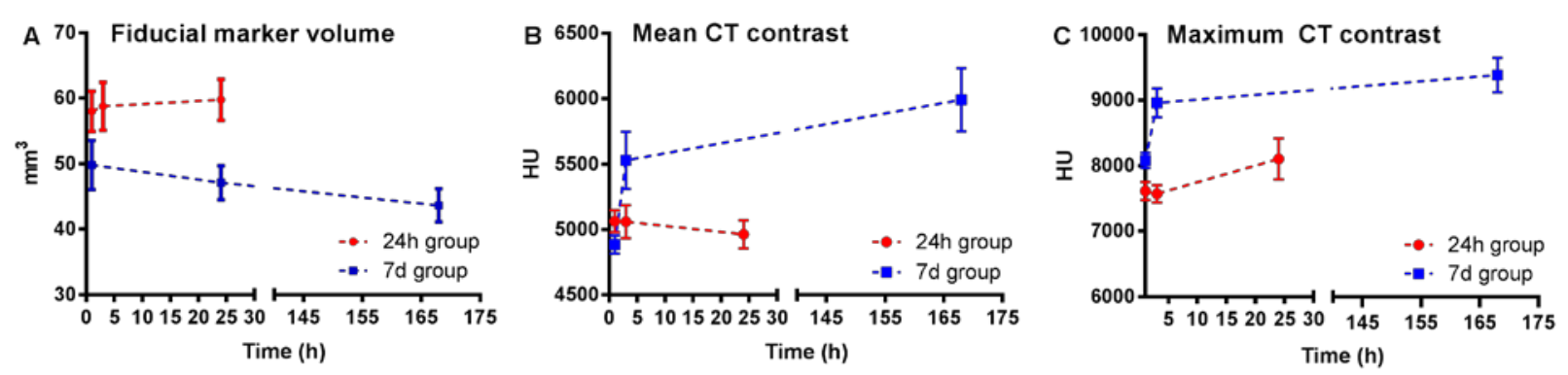

Fig. 3. Volume and CT contrast changes of tissue marker as a function of time. A) fiducial marker volume vs time, B) the mean CT contrast, and C) the maximum CT contrast of the tissue marker vs time.

\subsection{Biodistribution study}

In order to evaluate the leakage of radioactivity from the tissue marker, a biodistrubution study was performed. Tissue samples of organs of interest were weighed and well-counted after $1 \mathrm{~h}, 24 \mathrm{~h}$ and $168 \mathrm{~h}$ of implantation and standardized to the initial activity injected. The well-counting activities were reported in \%ID/g.

The results are shown in Fig. 4 (and Table S4) and clearly supports that the majority of the activity (>99\%) remained within the markers. A slight increase in radioactive density (\%ID/g) is observed over time from $204.3 \pm 64.5$ to $309 \pm 53.8 \% \mathrm{ID} / \mathrm{g}$ for the tissue marker. A Kruskal-Wallis comparison of the three groups was conducted in order to reveal significant difference between the groups. The result was non-significant ( $\mathrm{p}=0.37$ ). Therefore, no further post-test between the three groups were conducted. Trace amounts of ${ }^{125} \mathrm{I}$ activity were detected in the thyroid gland $1 \mathrm{~h}$ post injection and $0.06 \%$ (3.5 \% ID/g) of the total injected dose was detected in that organ 7 days post injection. For all other organs studied, very low levels of radioactivity $(<0.1 \% \mathrm{ID} / \mathrm{g})$ were detected. 

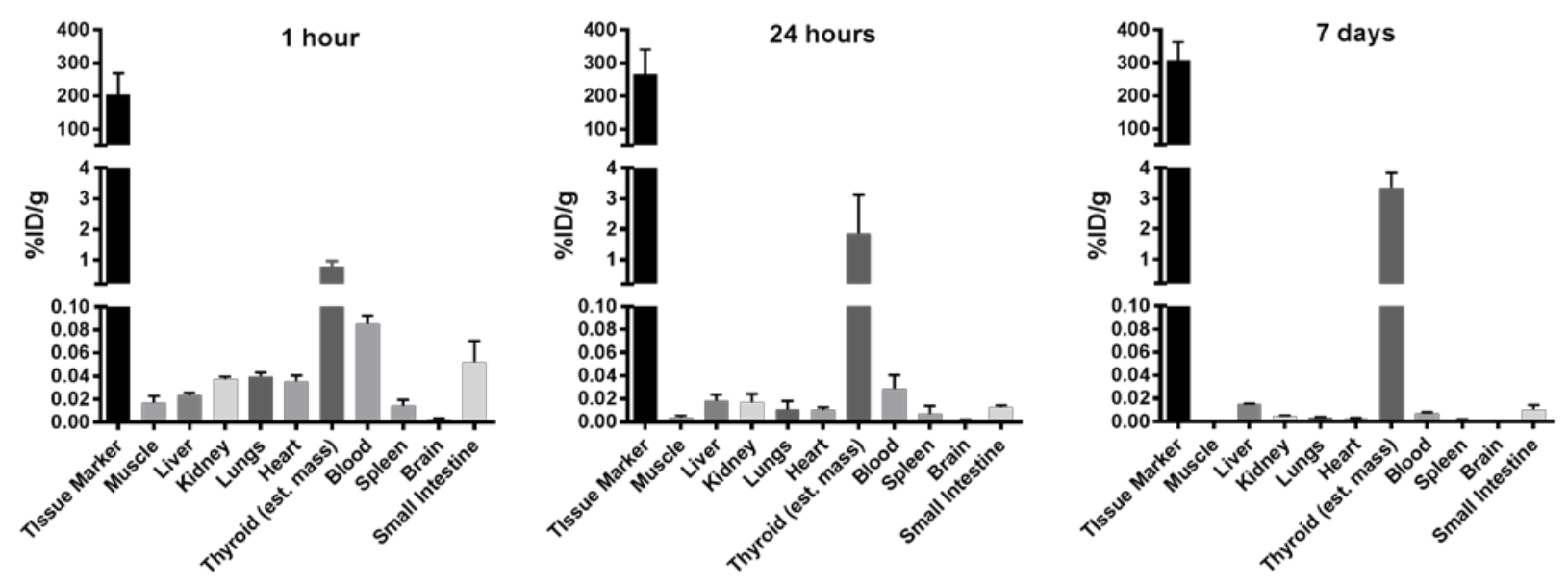

Fig. 4. Well counting of tissue/organs samples of the organs of interest at different times (decay corrected). The well-counted activities are reported in \%ID/g (See Material and Methods, section 2.5). The \%ID/g values for the tissue marker are; $1 \mathrm{~h}=204.3 \pm 64.5 \% \mathrm{ID} / \mathrm{g} ; 24 \mathrm{~h}=267.4 \pm 73.7 \% \mathrm{ID} / \mathrm{g}$ and $168 \mathrm{~h}=309 \pm 53.8 \% \mathrm{ID} / \mathrm{g}$. $(\mathrm{n}=4$, mean $\pm \mathrm{SEM})$.

\subsection{Dosimetry}

In order to evaluate whether the ${ }^{125}$ I-radiolabeled marker is suitable for use in breast cancer patients, a projection of the animal biodistribution to a human subject was performed employing the model derived in [24] using an anthropomorphic female phantom (see Supporting Information, Table S6). The model showed that after 7 days, the patient would have received an effective dose equivalent of $1.63 \mathrm{mSv} / \mathrm{MBq}$. The Olinda/EXM model [25] was also used to simulate the absorbed dose to the surrounding tissue and how the absorbed dose decays as a function of size of the implant (see Supporting Information, Table S5 and Figure S2).

\section{Discussion}


This paper presents the development of a ${ }^{125}$ I-radiolabeled injectable fiducial tissue marker for surgical guidance of non-palpable tumors in breast cancer. The ${ }^{125}$ I-radiolabeled injectable fiducial tissue marker is expected to be compatible with preceding neoadjuvant therapy, as the tissue marker advantageously can be placed 5-7 days prior to excision guided by the mammographic imaging. The high radiopacity of the developed tissue marker means that injection can be monitored in real-time using fluoroscopy and that the marker position can be confirmed by mammography or CT imaging prior to surgery. The gel-like implant was readily inserted using $27 \mathrm{G}$ hypodermic needles, which is expected to decrease patient discomfort.

The radioactive tracer $\left[{ }^{125} \mathbf{I}\right] 2$ was prepared via the synthetic route depicted in Scheme 1 . The radioiodination of $\mathbf{1}$ was designed so no thallium intermediates were part of the final product. The radioiodination itself took place under carrier-free conditions in accordance with the observation of McKillop et al. where aryl iodides were formed stoichiometrically from aryl-Tl(III)-(OOCCF 3$)_{2}$ using $\leq 1$ equiv. of $\mathrm{NaI}[26]$.

From the biodistribution analysis (Fig. 4), it is evident that the radioactivity is constant over time and retained within the tissue marker. The observed increase in radioactive density of the tissue marker over time could be explained by the slight reduction in volume of the tissue marker due to the ethanol efflux (Fig. 3A). This reduction in volume is further substantiated by the observed increase in mean and maximum CT contrast (Fig. 3B and 3C) (HU signal) of the tissue marker during the scanning period. However, no statistically significant difference $(p=0.37)$ between the radioactivity densities was found. The variance observed within each group could be explained by difficulty in sampling the tissue marker due to differences in texture at different time-points. This is explained by the efflux of ethanol leading to hardening of the gel-implant, which, at $1 \mathrm{~h}$ and $24 \mathrm{~h}$, is still on-going. 
The only measurable uptake was limited accumulation in the thyroid gland. This was expected to originate from small amounts of iodine not bound to the marker (see Supporting Information, Figure S1). It is worth emphasizing that the marker itself is removed surgically, minimizing exposure to nontumor tissue. The thyroid uptake was expected, as the gland is considered a risk organ when using radioactive iodide. One well-established way to lower the uptake is to saturate the thyroid gland by prescribing dietary iodine tablets prior to and during treatment [27].

The activity administered in this experiment is $1.9 \mathrm{MBq}$ (injection of $50 \mu \mathrm{L}$ of marker formulation with $38 \mathrm{MBq} \mathrm{mL}^{-1}$ ). With surgical removal of the tissue marker after seven days, the equivalent dose is $3.1 \mathrm{mSv}$ (0.05 $\mathrm{mSv}$ for the thyroid gland). Implantation of the marker seven days prior to surgery can be considered an extreme case compared to practice in the clinic. Despite this, the exposure level is low -3 times less than the dose received from a whole body CT scan, which is $10 \mathrm{mSv} / \mathrm{scan}$ [28]. As recently highlighted by Langhans et al., the optimal activity of a ${ }^{125}$ I radioactive seed is $0.5-1$ $\mathrm{MBq}$, in order to assure detection in the breast up to a depth of $8 \mathrm{~cm}$, as long as SLN mapping is not planned. If SLN is desired, an activity of $3 \mathrm{MBq}$ is recommended [13] .

From the absorbed dose calculated as a function of radius of the marker via the Olinda/EXM model (See Supporting Information, Figure S2), it is evident that high doses are administered locally when using small sizes of the tissue markers. A $50 \mu \mathrm{L}$ spherical tissue marker (radius of $2.3 \mathrm{~mm}$ ) would give a radiation exposure in the range of $80 \mathrm{~Gy} \cdot \mathrm{MBq}^{-1}$ locally to the surrounding tissue which with an activity administered of $1.9 \mathrm{MBq}$ would give a total amount of absorbed dose of $152 \mathrm{~Gy}$. This opens for the potential use of the material within the field of interstitial brachytherapy as high doses are absorbed locally to the surrounding tissue with less irradiation to healthy tissue [29]. For example, typically absorbed dose used in interstitial low-dose rate brachytherapy in prostate cancer is in the range of 145 Gy [30,31]. Additionally, the insertion using thin needles and the biocompatibility of the material offer clear advantages over the metal seeds currently used in brachytherapy. The need 
for novel biomaterials that are applicable in brachytherapy while being biocompatible and biodegradable has been highlighted in Puente et al. [32].

\section{Conclusions}

We have developed a short synthetic route to a precursor (1) that can be radioiodinated in good yields with high radiochemical purity. The ${ }^{125}$ I-radiolabeled injectable fiducial tissue marker comprising of ${ }^{\left[{ }^{125} \mathrm{I}\right] 2}$ and BioXmark ${ }^{\circledR}$, was injected $(50 \mu \mathrm{L})$ in the right flank of mice and was clearly visible by micro-CT imaging after 7 days, when the experiment was terminated. The gel-like implant was stable over this time and showed a good biodistribution profile. Based on the results presented here, it will be feasible to develop a ${ }^{125}$ I-radiolabeled injectable fiducial tissue marker for non-palpable breast cancer to the benefit of surgeons and patients.

\section{Acknowledgements}

This work has been funded by the Technical University of Denmark (DTU), the Danish Council for Strategic Research (Nanoguide, application no. 0603-00442B), and the Novo Nordisk Foundation. BioXmark ${ }^{\circledR}$ was kindly provided by Nanovi Radiotherapy A/S, Kgs. Lyngby, Denmark.

\section{Disclosures}

Rasmus I. Jølck is currently employed by Nanovi Radiotherapy A/S responsible for the commercial development of BioXmark ${ }^{\circledR}$. Thomas L. Andresen is a board member of Nanovi Radiotherapy A/S. All other authors report no conflicts of interest.

\section{Supplementary data}

Supplementary data related to this article can be found at 


\section{Bibliography}

[1] N.N.Y. Janssen, J. Nijkamp, T. Alderliesten, C.E. Loo, E.J.T. Rutgers, J.-J. Sonke, M.T.F.D. Vrancken Peeters, Radioactive seed localization in breast cancer treatment, Br. J. Surg. 103 (2016) 70-80. doi:10.1002/bjs.9962.

[2] M.E.M. van der Noordaa, K.E. Pengel, E. Groen, E. van Werkhoven, E.J.T. Rutgers, C.E. Loo, W. Vogel, M.J.T.F.D. Vrancken Peeters, The use of radioactive iodine-125 seed localization in patients with non-palpable breast cancer: A comparison with the radioguided occult lesion localization with 99m technetium, Eur. J. Surg. Oncol. 41 (2015) 553-558. doi:http://dx.doi.org/10.1016/j.ejso.2015.01.022.

[3] E.L. Postma, A.J. Witkamp, M.A.A.J. van den Bosch, H.M. Verkooijen, R. van Hillegersberg, Localization of nonpalpable breast lesions, Expert Rev. Anticancer Ther. 11 (2011) 1295-1302. doi:10.1586/era.11.116.

[4] U. Veronesi, N. Cascinelli, L. Mariani, M. Greco, R. Saccozzi, A. Luini, M. Aguilar, E. Marubini, Twenty-year follow-up of a randomized study comparing breast-conserving surgery with radical mastectomy for early breast cancer., N. Engl. J. Med. 347 (2002) 122732. doi:10.1056/NEJMoa020989.

[5] J. Rarick, B.F. Kimler, O. Tawfik, Comparison of margin status and lesional size between radioactive seed localized vs conventional wire localized breast lumpectomy specimens, Ann. Diagn. Pathol. 21 (2016) 47-52. doi:http://dx.doi.org/10.1016/j.anndiagpath.2016.01.003.

[6] M.W. Barentsz, M.A.A.J. van den Bosch, W.B. Veldhuis, P.J. van Diest, R.M. Pijnappel, A.J. Witkamp, H.M. Verkooijen, Radioactive seed localization for non-palpable breast cancer, Br. J. Surg. 100 (2013) 582-588. doi:10.1002/bjs.9068.

[7] H.A. Frank, F.M. Hall, M.L. Steer, Preoperative Localization of Nonpalpable Breast Lesions Demonstrated by Mammography, N. Engl. J. Med. 295 (1976) 259-260. doi:10.1056/NEJM197607292950506.

[8] M. Ahmed, I.T. Rubio, J.M. Klaase, M. Douek, Surgical treatment of nonpalpable primary invasive and in situ breast cancer, Nat Rev Clin Oncol. 12 (2015) 645-663. http://dx.doi.org/10.1038/nrclinonc.2015.161.

[9] G. Luini, A., Zurrida, S., Galimberti, V., Paganelli, Radioguided surgery of occult breast lesions, Eur. J. Cancer. 34 (1998) 204-205. doi:10.1016/S0959-8049(97)00376-6.

[10] J.W. Jakub, R.J. Gray, A.C. Degnim, J.C. Boughey, M. Gardner, C.E. Cox, Current status of radioactive seed for localization of non palpable breast lesions, Am. J. Surg. 199 (2010) 522528. doi:http://dx.doi.org/10.1016/j.amjsurg.2009.05.019.

[11] R.J. Gray, C. Salud, K. Nguyen, E. Dauway, J. Friedland, C. Berman, E. Peltz, G. Whitehead, C.E. Cox, Randomized Prospective Evaluation of a Novel Technique for Biopsy 
or Lumpectomy of Nonpalpable Breast Lesions: Radioactive Seed Versus Wire Localization, Ann. Surg. Oncol. 8 (2001) 711-715. doi:10.1007/s10434-001-0711-3.

[12] B. Pouw, I.M.C. van der Ploeg, S.H. Muller, R.A. Valdés Olmos, L.K. Janssen-Pinkse, H.S.A. Oldenburg, M.T.F.D. Vrancken Peeters, Simultaneous use of an 125I-seed to guide tumour excision and 99mTc-nanocolloid for sentinel node biopsy in non-palpable breastconserving surgery, Eur. J. Surg. Oncol. 41 (2015) 71-78. doi:http://dx.doi.org/10.1016/j.ejso.2014.10.046.

[13] L. Langhans, T.L. Klausen, T.F. Tvedskov, M.-L. Talman, P.S. Oturai, I. Vejborg, N.K. and B. Hesse, Preparation and Administration of I-125 Labeled Seeds for Localization of Nonpalpable Breast Lesions, Curr. Radiopharm. 9 (2016) 143-149. doi:http://dx.doi.org/10.2174/1874471008666150804111121.

[14] Y. Lu, Y. Yu, X. Tang, Sucrose acetate isobutyrate as an In Situ forming system for sustained risperidone release, J. Pharm. Sci. 96 (2007) 3252-3262. doi:10.1002/jps.21091.

[15] Y. Lu, H. He, Y. Cui, X. Tang, [Rheological properties of sucrose acetate isobutyrate in situ gel]., Yao Xue Xue Bao. 42 (2007) 445-9. http://europepmc.org/abstract/MED/17633217 (accessed August 18, 2016).

[16] X. Lin, S. Yang, J. Gou, M. Zhao, Y. Zhang, N. Qi, H. He, C. Cai, X. Tang, P. Guo, A novel risperidone-loaded SAIB-PLGA mixture matrix depot with a reduced burst release: effects of solvents and PLGA on drug release behaviors in vitro/in vivo, J. Mater. Sci. Mater. Med. 23 (2012) 443-455. doi:10.1007/s10856-011-4521-2.

[17] R.I. Jølck, J.S. Rydhög, A.N. Christensen, A.E. Hansen, L.M. Bruun, H. Schaarup-Jensen, A.S. von Wenck, B. Børresen, A.T. Kristensen, M.H. Clausen, A. Kjær, K. Conradsen, R. Larsen, P.M. af Rosenschöld, T.L. Andresen, Injectable Colloidal Gold for Use in Intrafractional 2D Image-Guided Radiation Therapy, Adv. Healthc. Mater. 4 (2015) 856863. doi:10.1002/adhm.201400651.

[18] J. Scherman Rydhög, R. Irming Jølck, T.L. Andresen, P. Munck af Rosenschöld, Quantification and comparison of visibility and image artifacts of a new liquid fiducial marker in a lung phantom for image-guided radiation therapy, Med. Phys. 42 (2015) 28182826. doi:10.1118/1.4919616.

[19] J.S. Rydhög, S.R. Mortensen, K.R. Larsen, P. Clementsen, R.I. Jølck, M. Josipovic, M.C. Aznar, L. Specht, T.L. Andresen, P.M. af Rosenschöld, G.F. Persson, Liquid fiducial marker performance during radiotherapy of locally advanced non small cell lung cancer, Radiother. Oncol. 121 (2016) 64-69. doi:http://dx.doi.org/10.1016/j.radonc.2016.06.012.

[20] J. Scherman Rydhög, R. Perrin, R.I. Jølck, F. Gagnon-Moisan, K.R. Larsen, P. Clementsen, S. Riisgaard de Blanck, G. Fredberg Persson, D.C. Weber, T. Lomax, T.L. Andresen, P. Munck af Rosenschold, Liquid fiducial marker applicability in proton therapy of locally advanced lung cancer, Radiother. Oncol. (2017). doi:10.1016/j.radonc.2016.12.027. 
[21] R.I. Jølck, T. Binderup, A.E. Hansen, J.B. Scherman, P. Munch af Rosenschold, A. Kjaer, T.L. Andresen, Injectable colloidal gold in a sucrose acetate isobutyrate gelating matrix with potential use in radiation therapy., Adv. Healthc. Mater. 3 (2014) 1680-7. doi:10.1002/adhm.201300668.

[22] M.H. Rønnest, F. Nissen, P.J. Pedersen, T.O. Larsen, W. Mier, M.H. Clausen, A Mild Method for Regioselective Labeling of Aromatics with Radioactive Iodine, European J. Org. Chem. 2013 (2013) 3970-3973. doi:10.1002/ejoc.201300419.

[23] S. Dobiasch, S. Kampfer, R. Burkhardt, D. Schilling, T.E. Schmid, J.J. Wilkens, S.E. Combs, BioXmark for high-precision radiotherapy in an orthotopic pancreatic tumor mouse model, Strahlentherapie Und Onkol. (2017). doi:10.1007/s00066-017-1193-y.

[24] A.S. Kirschner, R.D. Ice, W.H. Beierwaltes, Radiation Dosimetry of 131I-19Iodocholesterol, J. Nucl. Med. . 14 (1973) 713-717. http://jnm.snmjournals.org/content/14/9/713.short.

[25] M.G. Stabin, R.B. Sparks, E. Crowe, OLINDA/EXM: The Second-Generation Personal Computer Software for Internal Dose Assessment in Nuclear Medicine, J. Nucl. Med. . 46 (2005) 1023-1027. http://jnm.snmjournals.org/content/46/6/1023.abstract.

[26] A. McKillop, J.D. Hunt, M.J. Zelesko, J.S. Fowler, E.C. Taylor, G. McGillivray, F. Kienzle, Thallium in organic synthesis. XXII. Electrophilic aromatic thallation using thallium(III) trifluoroacetate. Simple synthesis of aromatic iodides, J. Am. Chem. Soc. 93 (1971) 48414844. doi:10.1021/ja00748a029.

[27] P.B. Zanzonico, D. V Becker, Effects of time of administration and dietary iodine levels on potassium iodide (KI) blockade of thyroid irradiation by 131I from radioactive fallout, Health Phys. 78 (2000) 660-7.

[28] D.H. authority (SIS), Radiation Guide - Ionizing radiation, (2013).

[29] L.S.S.-G. Organisation for Economic Co-Operation and Development - Nuclear Energy Agency - OECD/NEA 12 boulevard des Iles, F-92130 Issy-les-Moulineaux (France), Evolution of ICRP Recommendations 1977, 1990 and 2007 Changes in Underlying Science and Protection Policy and case study of their impact on European and UK domestic regulation, Organisation for Economic Co-Operation and Development - Nuclear Energy Agency, Nuclear Energy Agency of the OECD (NEA), 2011.

[30] M.W.T. Chao, P. Grimm, J. Yaxley, R. Jagavkar, M. Ng, N. Lawrentschuk, Brachytherapy: state-of-the-art radiotherapy in prostate cancer, BJU Int. 116 (2015) 80-88. doi:10.1111/bju.13252.

[31] S.E.M. Langley, R.W. Laing, Iodine seed prostate brachytherapy: an alternative first-line choice for early prostate cancer, Prostate Cancer Prostatic Dis. 7 (2004) 201-207. http://dx.doi.org/10.1038/sj.pcan.4500727. 
[32] P. de la Puente, A.K. Azab, Delivery systems for brachytherapy, J. Control. Release. 192 (2014) 19-28. doi:http://dx.doi.org/10.1016/j.jconrel.2014.06.057. 